\title{
Pleuroparenchymal lung disease secondary to nonoccupational exposure to vermiculite
}

\author{
Fahad Al-Ghimlas MD, Victor Hoffstein PhD MD FRCPC FCCP
}

F Al-Ghimlas, V Hoffstein. Pleuroparenchymal lung disease secondary to nonoccupational exposure to vermiculite. Can Respir J 2007;14(3):164-166.

\begin{abstract}
An unusual case of pleuroparenchymal lung disease caused by the inhalation of vermiculite dust, presumably containing asbestos fibers is described. The uniqueness of the case lies in the very indirect nature of exposure - the wife of a factory owner, rather than a worker exposed to asbestos, whose factory manufactured vermiculite. The present case illustrates the importance of taking careful occupational histories of all household members when presented with a patient whose chest radiograph exhibits features consistent with asbestos exposure.
\end{abstract}

\section{Une maladie pulmonaire pleuroparenchyma- teuse secondaire à une exposition non professionnelle à la vermiculite}

\begin{abstract}
Nous décrivons un cas inhabituel de maladie pulmonaire pleuroparenchymateuse causée par l'inhalation de poussière de vermiculite, contenant probablement des fibres d'amiante. La particularité du cas provient de la nature très indirecte de l'exposition : la femme d'un travailleur d'usine, plutôt qu'un travailleur exposé à l'amiante, dont l'usine fabriquait de la vermiculite. Le présent cas illustre l'importance de s'attarder aux antécédents de travail de tous les membres de la maisonnée lorsqu'à la radiographie thoracique, le patient présente des caractéristiques d'exposition à l'amiante.
\end{abstract}

Key Words: Asbestosis; Pleural disease; Second-hand exposure; Vermiculite

\begin{abstract}
A sbestos-associated lung disease may occur without direct occupational exposure to asbestos, such as in the spouses of exposed workers. It is suspected that the disease is caused by the direct inhalation of asbestos fibers contained in work clothes. We describe the case of a woman who developed lung disease from an even less direct exposure. Her husband owned a factory manufacturing vermiculite, which may contain an asbestiform amphibole mineral.
\end{abstract}

\section{CASE PRESENTATION}

A previously healthy, 77-year-old woman, who was born and raised in Canada, was scheduled to have an elective abdominal aortic aneurysm repair. A routine chest radiograph was obtained and was found to be abnormal. The patient was referred for further evaluation.

She had stopped smoking 15 years earlier after 65 packyears. She had no previous history of lung disease, and had complained of occasional night sweats, poor appetite and $7 \mathrm{~kg}$ of weight loss - all within the previous six months.

Between 1955 and 1965, she had been married to the owner of a vermiculite processing factory. She had noticed this material on her husband's pants and inside the cuffs; she commented that whenever she took his pants to be dry cleaned or hung them in a closet, there would be 'gold dust' scattered on the floor. From time to time, she had asked her husband to bring some of this material home and had used it in the garden as a soil conditioner. The total duration of her exposure to this material lasted 10 years, until her husband's death from a nonpulmonary cause.

On examination, she was a thin woman who did not look ill. There was no finger clubbing, and her chest examination revealed bibasilar end-inspiratory crackles.

A chest radiograph showed dense basilar reticulonodular interstitial opacifications (Figure 1). A computed tomography (CT) scan of the thorax (Figure 2) confirmed these findings, showing diaphragmatic calcified pleural plaques and interstitial opacities. Spirometry showed a forced vital capacity (FVC) of $2.0 \mathrm{~L}$ ( $74 \%$ of predicted), a forced expiratory volume in $1 \mathrm{~s}$ of $1.5 \mathrm{~L}$ (78\% of predicted) and a forced expiratory volume in $1 \mathrm{~s} / \mathrm{FVC}$ ratio of 0.75 (predicted ratio 0.71 ). Single-breath diffusing capacity for carbon monoxide was reduced at $65 \%$ of predicted. She did not wish to proceed with measurements of lung volumes by body plethysmography, but her single-breath helium dilution total lung capacity was $3.1 \mathrm{~L}$ (65\% of predicted).

At first, she refused bronchoscopy because she felt well and did not wish to have any pulmonary investigations. However, following her surgery, immediately before extubation, she agreed to undergo bronchoscopy without transbronchial biopsy. Consequently, only bronchial washings and bronchial brushings, but unfortunately no tissue, were obtained. Cytology of the specimens showed no malignant cells; bacterial and fungal cultures were negative. 


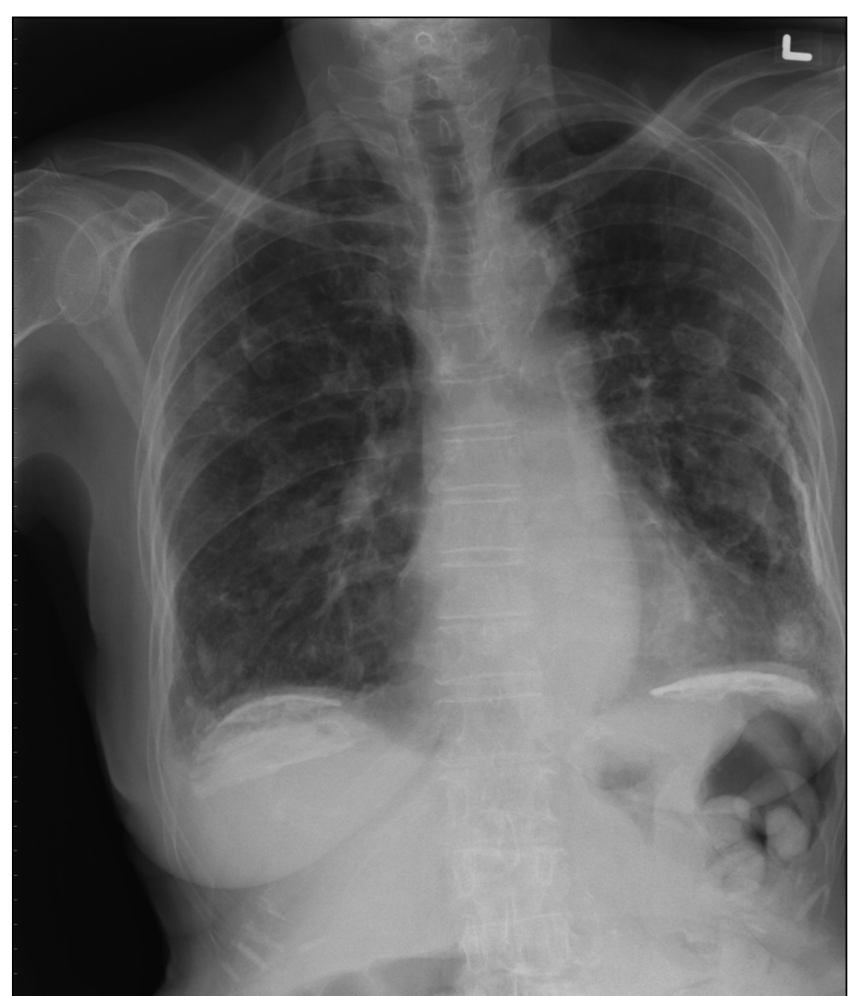

Figure 1) A chest radiograph showing diaphragmatic and pleural calcifications, as well as parenchymal infiltrates

\section{DISCUSSION}

Although cases of asbestosis and pleural disease in workers exposed to asbestos and in their family members have been well described, our case is unique because of the following aspects: the exposure had been even less direct (ie, from the husband's clothes); the 'index case' was not an asbestos worker but a factory owner; the material was not pure asbestos, but vermiculite, which undoubtedly contained tremolite asbestos; and the patient had remained completely asymptomatic for many years. It is only incidental radiographic abnormalities that prompted a review of our patient's medical history and exposures, eventually leading to the diagnosis of asbestosis and pleural plaques secondary to inhalation of vermiculite dust.

Vermiculite is a mica-type mineral (1), the ore of which may contain several minerals, including asbestos. It is mined, crushed and then heated to form a lightweight aggregate. It is processed to produce a final product, which is a fine dust particle. This product has many uses: as construction material mainly for insulation, in composite cements, as a filter medium and in horticulture for soil conditioning. It is generally thought to be a safe material. However, vermiculite ore may be contaminated with tremolite asbestos. The latter is not mined or used commercially, but is a very ubiquitous material, representing the most common amphibole fiber in the lungs of urbanites. Review of the information regarding health consequences of exposure to vermiculite led the American Thoracic Society to conclude that when the cumulative exposure to tremolite is high, disease such as lung cancer and mesothelioma may occur (2).

There are several cohort studies examining the effects of vermiculite in workers and in their family members. These studies indicate that exposure to vermiculite may produce
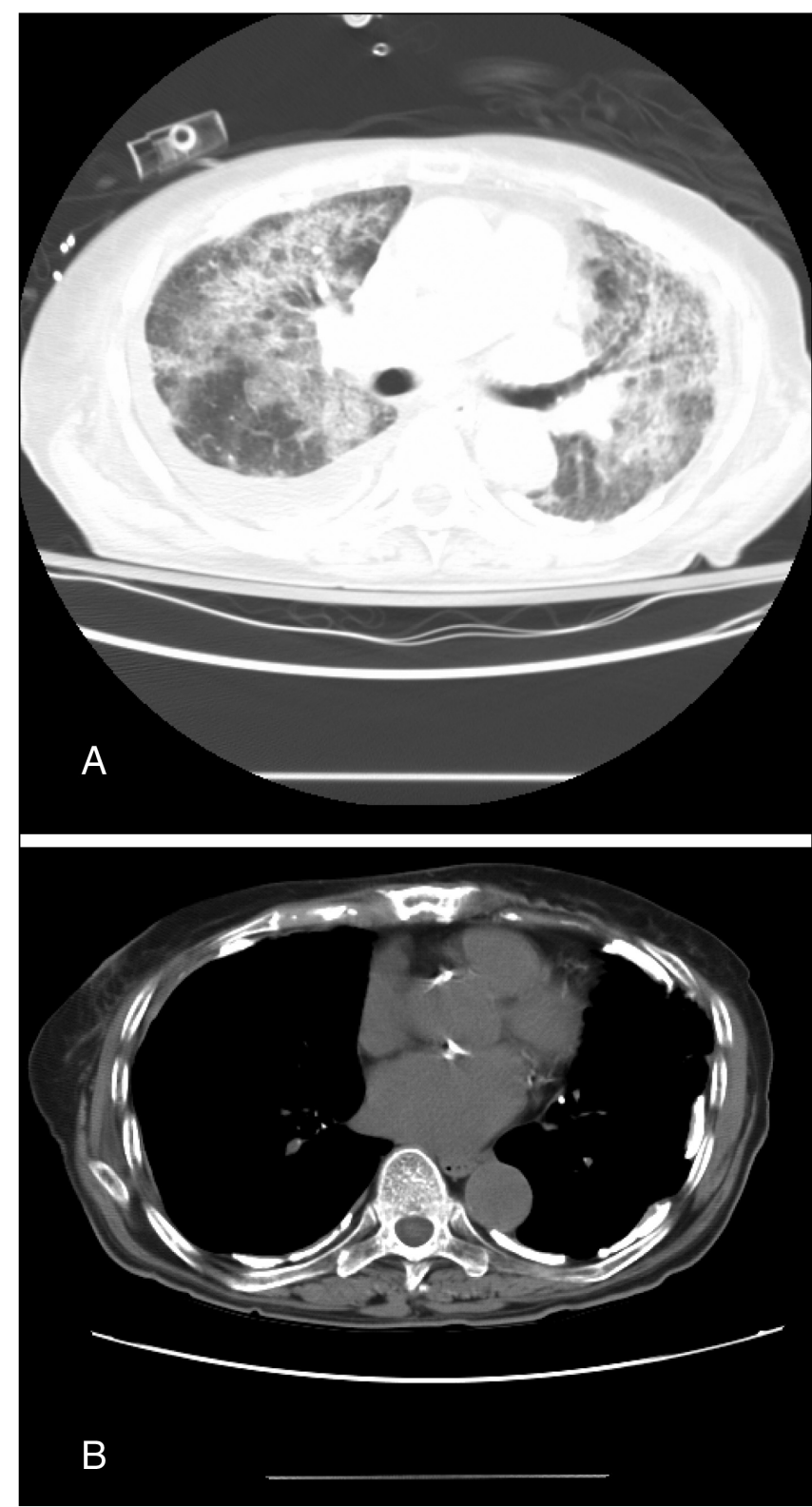

Figure 2) Representative sections of a computed tomography scan of the thorax showing interstitial disease (A) and pleural calcifications (B)

radiographic abnormalities, changes in pulmonary function, clinical symptoms and increased risk of lung cancer, as well as nonmalignant respiratory disease.

Radiographic abnormalities are confined primarily to the pleura, and interstitial infiltrates are rare. The prevalence of radiographic abnormalities differs depending on the study, undoubtedly due to the heterogeneity of the study population and methodology. For example, Lockey et al (3) found that in 512 exposed workers, 96\% had normal chest radiographs, whereas Whitehouse (4) found exactly the opposite - over $96 \%$ of 123 subjects had abnormal chest radiographs or highresolution CT of the thorax. Because high-resolution CT was not used consistently in all studies, it is possible that the actual prevalence of radiographic abnormalities is underestimated.

Pulmonary function abnormalities are generally mild and appear to be more related to smoking than to cumulative exposure to vermiculite. However, exposed workers show more rapid 
decline in lung function than expected. For example, after three years of follow-up of an exposed cohort residing in Libby, Montana, USA, there were accelerated declines in FVC, total lung capacity and single-breath diffusing capacity for carbon monoxide, approximately $2 \%$ to $3 \%$ per year (4).

The clinical symptoms of exposure are cough, exertional dyspnea and pleuritic chest pain. Cough appears to be related primarily to cigarette smoking, but dyspnea and pleuritic chest pain are independently related to cumulative fibre exposure (3).

The clinical evidence describing the association between exposure to vermiculite and disease has been summarized by several investigators. One of the first reports (5) described the cohort of workers in Libby, where vermiculite ore is heavily contaminated with tremolite asbestos. The authors found an increased risk of mortality from respiratory cancer, mesothelioma and pulmonary fibrosis. This finding was subsequently confirmed by Amandus and Wheeler (6) in a cohort of 575 men employed in a mine in Libby. McDonald et al (7) showed that this increased risk was due to tremolite asbestos contaminating vermiculite ore; in workers from a mine in South Carolina, USA, where tremolite asbestos contamination was minimal, no increased risk of malignancy or other respiratory disease was found. Finally, in a recent study of a cohort of 406 vermiculite workers from Libby, Montana, employed before 1963 and followed until 1999, McDonald et al (8) found that exposure to tremolite fibers carries increased RR of death from lung cancer (RR 3.20 or less) and nonmalignant respiratory disease (RR 3.11 or less), as well as mortality from all causes (RR 1.42 or less).

All of the above studies examined workers currently working with vermiculite, those who worked with it in the past or, less frequently, family members of workers living in the same dwelling. There are very few reports of asbestosis or pleural plaques in end-users of vermiculite. One case report (9) described a 65-year-old accountant who had spent two summers working with insulation 48 years previously. He developed gradually progressive pleural disease and pulmonary fibrosis at 50 years of age and died of respiratory failure at 65 years of age. Another case report (10) described an 82-year-old man who had worked for 17 years (beginning at 49 years of age) packing flammable cans of paint into boxes containing vermiculite. We can now add another case to the literature of even more indirect exposure - the inhalation of vermiculite dust from the husband's clothes and from using it infrequently during summers while doing home gardening.

\section{CONCLUSION}

We emphasize that in dealing with a patient (man or woman) who presents with radiographic findings of asbestosis and pleural plaques, but who denies exposure to asbestos, physicians should not only be aware of other scenarios of exposure, but should also inquire about exposure to other materials that may have contained asbestos fibers.

DISCLOSURE: The authors of this report, Drs Fahad Al-Ghimlas and Victor Hoffstein, have no conflicts of interest.

\section{REFERENCES}

1. Addison J. Vermiculite: A review of the mineralogy and health effects of vermiculite exploitation. Regul Toxicol Pharmacol 1995;21:397-405.

2. Health effects of tremolite. This official statement of the American Thoracic Society was adopted by the ATS Board of Directors, June 1990. Am Rev Respir Dis 1990;142:1453-8.

3. Lockey JE, Brooks SM, Jarabek AM, et al. Pulmonary changes after exposure to vermiculite contaminated with fibrous tremolite. Am Rev Respir Dis 1984;129:952-8.

4. Whitehouse AC. Asbestos-related pleural disease due to tremolite associated with progressive loss of lung function: Serial observations in 123 miners, family members, and residents of Libby, Montana. Am J Ind Med 2004;46:219-25.

5. McDonald JC, McDonald AD, Armstrong B, Sebastien P. Cohort study of mortality of vermiculite miners exposed to tremolite. Br J Ind Med 1986;43:436-44.

6. Amandus HE, Wheeler R. The morbidity and mortality of vermiculite miners and millers exposed to tremolite-actinolite: Part II. Mortality. Am J Ind Med 1987;11:15-26.

7. McDonald JC, McDonald AD, Sebastien P, Moy K. Health of vermiculite miners exposed to trace amounts of fibrous tremolite. Br J Ind Med 1988;45:630-4.

8. McDonald JC, Harris J, Armstrong B. Mortality in a cohort of vermiculite miners exposed to fibrous amphibole in Libby, Montana. Occup Environ Med 2004;61:363-6.

9. Wright RS, Abraham JL, Harber P, Burnett BR, Morris P, West P. Fatal asbestosis 50 years after brief high intensity exposure in a vermiculite expansion plant. Am J Respir Crit Care Med 2002;165:1145-9.

10. Howard TP. Pneumoconiosis in a vermiculite end-product user. Am J Ind Med 2003;44:214-7. 


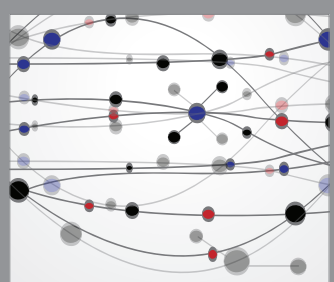

The Scientific World Journal
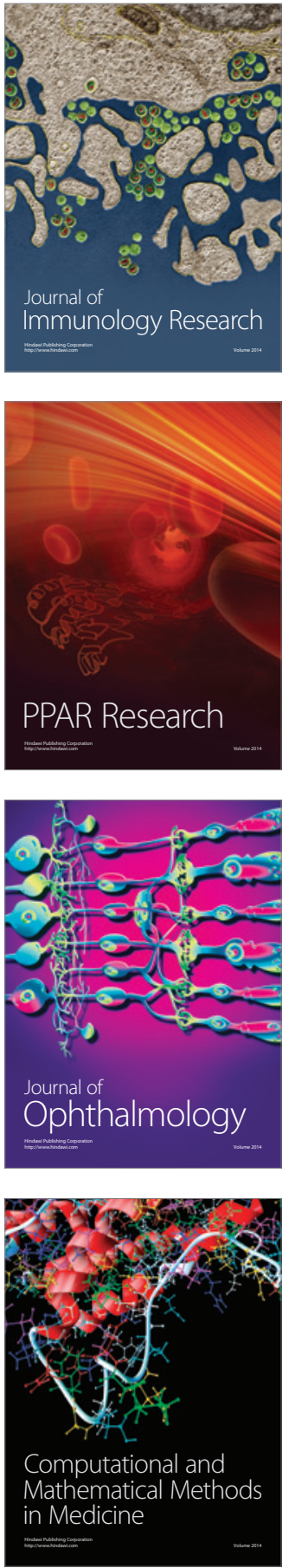

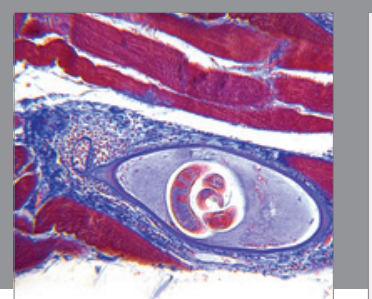

Gastroenterology Research and Practice

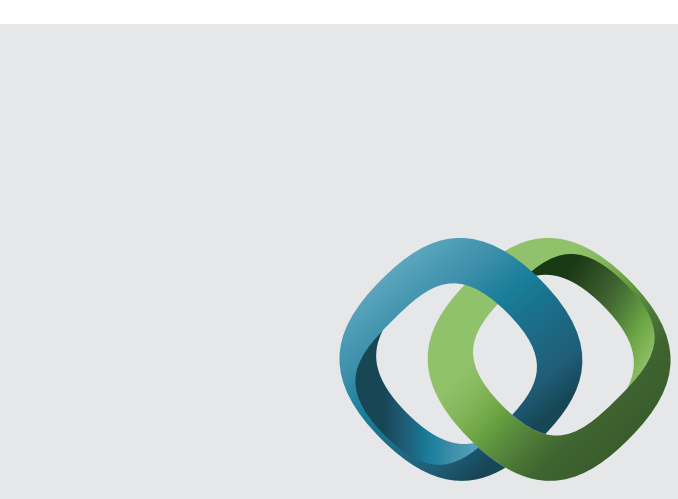

\section{Hindawi}

Submit your manuscripts at

http://www.hindawi.com
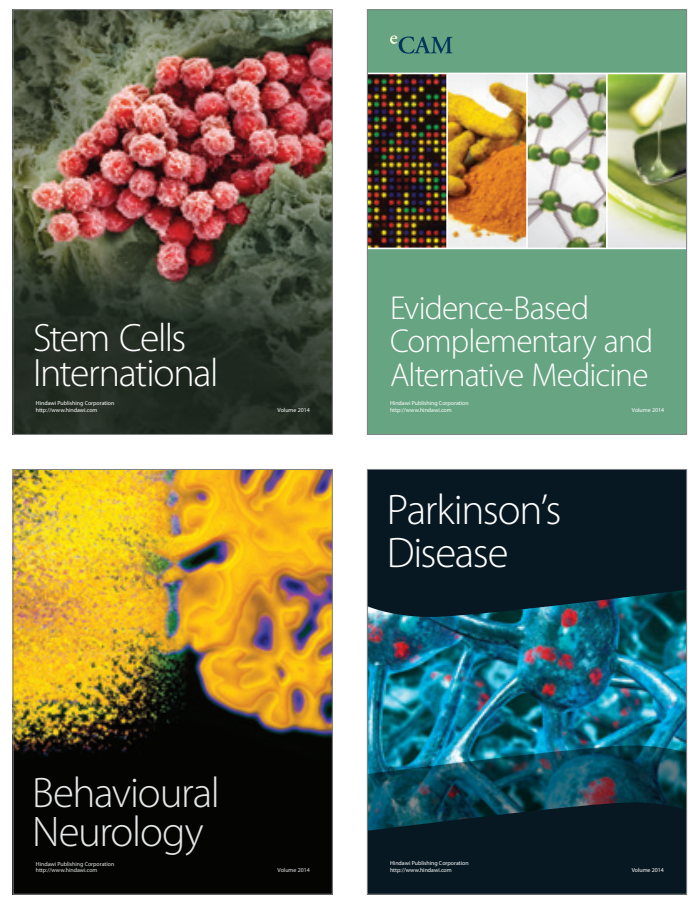
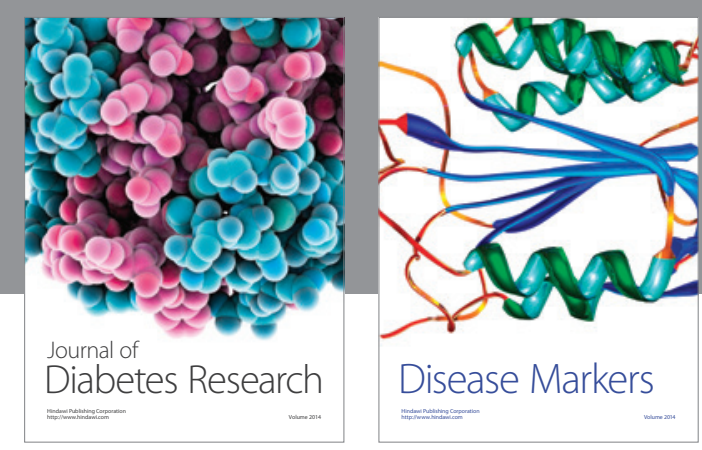

Disease Markers
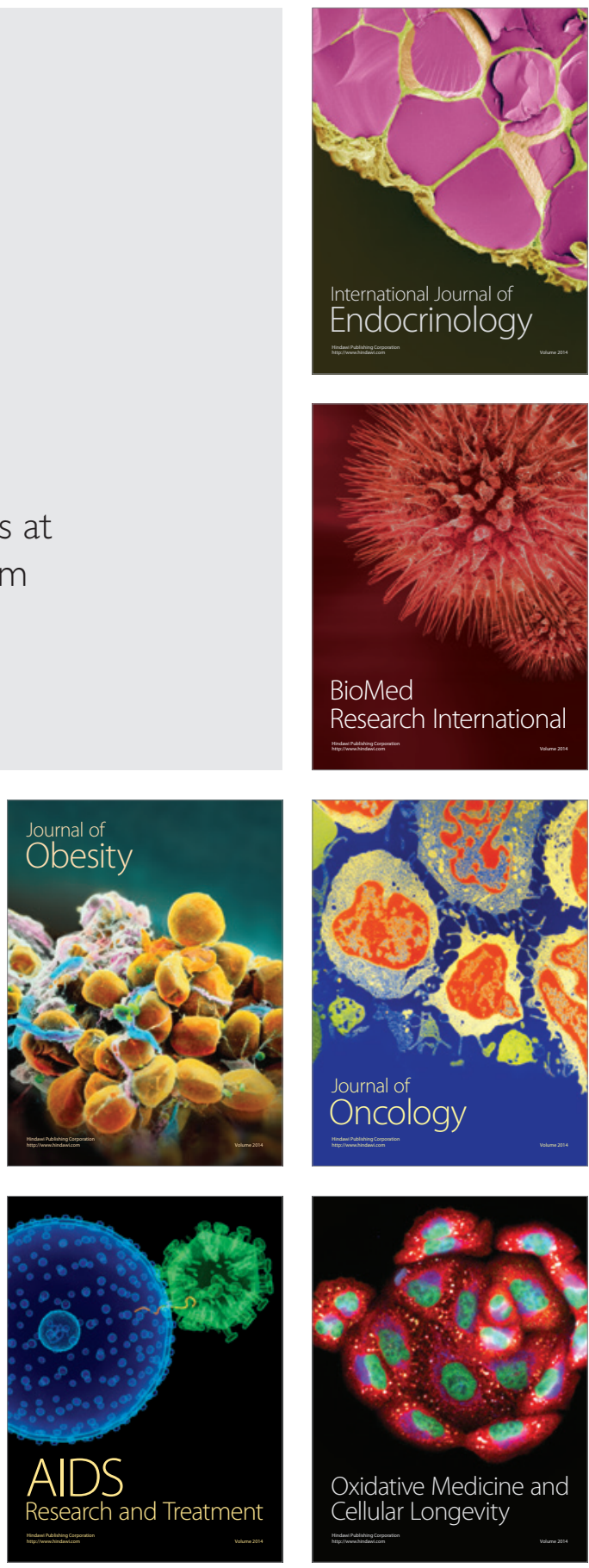